\title{
RISK ANALYSIS ON CONCEPTUAL DESIGN OF SOEKARNO-HATTA INTERNATIONAL AIRPORT RAIL LINK PROJECT USING VALUE ENGINEERING
}

\author{
Herawati Z. Rahman ${ }^{1}$, Mohammed A. Berawi ${ }^{2}$, Suci I. Susilowati ${ }^{2}$, Perdana Miraj ${ }^{2}$, Jade S. \\ Petroceany $^{2}$
}

1. Department of Civil Engineering, Faculty of Engineering, University of Pancasila, Depok, 16424, Indonesia

2. Department of Civil Engineering, Faculty of Engineering, Universitas Indonesia, Depok, 16424, Indonesia

(Received: December 2014 / Revised: January 2015 / Accepted: April 2015)

\begin{abstract}
The Soekarno-Hatta International Airport Rail Link (SHIARL) project is arguably one of the best solutions to reduce uncertainty in travel time and to improve accessibility to and from Soekarno-Hatta International Airport. Due to low feasibility assessments, the private sector is holding back on their investment for this mega project infrastructure; therefore, a comprehensive study is required to improve project return on investment attractiveness. This study mainly identifies major risks and mitigation strategies by combining Value Engineering (VE) and Risk Management (RM). Questionnaire surveys and risk analysis will be used to respond to the research objectives and the analysis will be presented in the methodology section. The VE process produces additional functions as the integration of the MRT line, the Flood Control Tunnel (PRASTI), the Rail Link and infrastructure utilities which are expected not only to solve transportation problems, but also flood control problems in Jakarta. On the other hand, the RM process points out route selection error as a major risk that has to be mitigated for a successful project.
\end{abstract}

Keywords: Infrastructure; Railway; Risk Mitigation; Value Engineering.

\section{INTRODUCTION}

In 2010 Soekarno-Hatta International Airport was noted as the $12^{\text {th }}$ world's busiest airport ( $4^{\text {th }}$ in Asia) due to its passenger flow rate (Land Transportation Journal, 2010). As one of the busiest airports in the world, Soekarno-Hatta International Airport has had significant passenger growth rates at around $14 \%$ per year and it serves on average 44 million passengers per year.

Access to the airport highly depends on inter-city highways and the interchanges to the Sediyatmo Highway. These highways have suffered huge traffic volume increases which cause congestion and travel time uncertainty for airport passengers. On the other hand, flooded conditions are also worsening accessibility problems and potentially reducing transportation sector performance. In such conditions, alternative modes of transportation such as the construction of through-rail links are required to provide high mobility of passengers and goods to and from the airport. The Sydney Airport Train and the Hong Kong Airport Express are two examples of airport trains that offer users a swift and comfortable mass transport experience from the airport to the city (Tang and Lo, 2008; Zou et al., 2008).

\footnotetext{
* Corresponding author. E-mail address: herazetha@gmail.com, Tel.: +62-8161971394
} 
Therefore, the SHIARL project is expected to increase predictability and punctuality and to provide a better mass transportation system to connect Soekarno-Hatta International Airport Airport to Greater Jakarta. The SHIARL feasibility project was initially issued in 2002 by PT.RAILINK and offered to investors in the Infrastructure Summit during 2005 and 2006.

Due to the failure of its financial feasibility, the project was redeveloped to attract private investors. In the Public Private Partnership (PPP) Book 2013 published by the Ministry of National Development Planning, (Bappenas), Republic of Indonesia, the status of the SHIARL project was downgraded from a ready-to-offer project into a priority project. The decreased status shows a lack of quality on project preparation for the PPP projects in Indonesia. Therefore, the feasibility study as part of the investment process stage in the PPP scheme plays an important role in attracting private sector investment.

A key for achieving feasibility of a project is related to how to deliver expected value for money (VfM) (Yongjian et al., 2010; Xiao Hua and Zhang, 2011; Berawi et al., 2014). $\mathrm{VtM}$ is defined as the use of public funds for infrastructure project by creating innovative construction techniques, creative financing and private sector involvement (Berawi and Susantono, 2012; Grimsey and Lewis, 2005). VfM reflects on project feasibility through proportional risk sharing between the private sector and the government. In many cases, a risk evaluation methodology has been used, yet how to achieve VfM in this particular feasibility study was not clearly defined. Another methodology to produce VfM is by using Value Engineering (VE).

The Value Engineering (VE) approach also involves the activities of risk assessment and risk analysis (Dell'Isola, 1997), particularly in the project initiation phase which is an effective way to control the process, in order to create risk mitigation and to reduce risk impact to the project. Both Value Engineering (VE) and Risk Management (RM) are expected to maximize the value of a project and provide recommendations for decision makers in terms of technical, financial and regulatory strategies.

\section{METHODOLOGY}

This research uses quantitative and qualitative methods. Quantitative methods included distributing a questionnaire survey to stakeholders in the infrastructure sector, particularly those in the railway infrastructure sector, which consists of state-owned enterprises, private companies, investors, ministries, and academics. The risk questionnaire survey uses the Likert scale in identifying the main risks in the SHIARL project with a total of 33 returned questionnaires. Meanwhile, qualitative methods were utilized to clarify and elaborate on the results of the questionnaire through Focus Group Discussions (FGD). Risk variables in the questionnaire data were analyzed using descriptive analysis, inferential statistics, the Analytic Hierarchy Process (AHP), risk levels, and risk factor analysis.

The AHP is a mathematical model that is used as a decision making method by integrating different units of measurements into a single scale. The AHP is widely used by academics and researchers and its application helps to solve complex problems by structuring a hierarchy of criteria and then comparing and prioritizing related elements by drawing various considerations in order to develop priorities. (Janic and Reggiani, 2002; Yoo and Choi, 2006).

Numerous academics have defined recommended steps in conducting an AHP (Yoo and Choi, 2006; Zietsman and Vanderschuren, 2014): These steps are used to:

- Define problems and potential solutions;

- Structure a hierarchy from objectives, criteria, sub-criteria and alternative selections; 
- Construct pairwise comparisons for each element at each objective level by using the relative scale of importance as shown in Table 1.

- Calculate the Eigen value;

- Conduct a consistency analysis.

The AHP method allows inconsistency in judgment and consequently, it provides a method to measure the inconsistency in each set of judgments. This is determined by the Consistency Ratio (CR).

$$
\begin{aligned}
& C R=\frac{C I}{R I} \\
& C I=\frac{\left(\lambda_{\text {maks }}-n\right)}{(n-1)}
\end{aligned}
$$

Where:

CI $=$ Consistency Index

$\lambda_{\text {maks }}=$ Eigenvalue maximum

$n \quad=$ Matrix dimension

Table 1. Relative Scale of Importance in AHP

\begin{tabular}{cll}
\hline $\begin{array}{c}\text { Intensity of } \\
\text { importance }\end{array}$ & Definition & Explanation \\
\hline 1 & Equal importance & $\begin{array}{l}\text { Two elements contribute equally to the objective } \\
\text { Experience and judgment slightly favor one } \\
\text { element over another } \\
\text { Experience and judgment strongly favor one } \\
\text { element over another } \\
\text { One element is favored very strongly over } \\
\text { another, its dominance is demonstrated in practice } \\
\text { The evidence favoring one element over another is } \\
\text { of the highest possible order of affirmation }\end{array}$ \\
\hline
\end{tabular}

$2,4,6,8$ can be used to express intermediate values, $1.1,1.2$, etc. for elements that are very close in importance

Table 2. Random Index (RI) Value

\begin{tabular}{ccccccccccccccc}
\hline $\begin{array}{c}\text { Matrix } \\
\text { Dimension }\end{array}$ & 1,2 & 3 & 4 & 5 & 6 & 7 & 8 & 9 & 10 & 11 & 12 & 13 & 14 & 15 \\
\hline RI & 0,00 & 0,58 & 0,90 & 1,12 & 1,24 & 1,32 & 1,41 & 1,45 & 1,49 & 1,51 & 1,48 & 1,56 & 1,58 & 1,59
\end{tabular}

The risk level is then conducted to determine risk level ranking of risk variables affected by two criteria: probability and impact. The matrix risk level as shown in Table 3, which will calculate each sample and convert them as follows: $\mathrm{L}=1, \mathrm{M}=2, \mathrm{~S}=3, \mathrm{H}=4$. This value will be used as data input for further risk analysis. 
Table 3. Matrix Risk Level

\begin{tabular}{|c|c|c|c|c|c|}
\hline Probability & $\begin{array}{c}\text { Insignificant } \\
1\end{array}$ & $\begin{array}{c}\text { Minor } \\
2\end{array}$ & $\begin{array}{c}\text { Impact } \\
\text { Moderate } \\
3\end{array}$ & $\begin{array}{c}\text { Major } \\
4\end{array}$ & $\begin{array}{c}\text { Catastrophic } \\
5\end{array}$ \\
\hline Very High (A) & $\mathrm{S}$ & $\mathrm{S}$ & $\mathrm{H}$ & $\mathrm{H}$ & $\mathrm{H}$ \\
\hline High (B) & M & S & S & $\mathrm{H}$ & $\mathrm{H}$ \\
\hline Moderate (C) & $\mathrm{L}$ & M & S & $\mathrm{H}$ & $\mathrm{H}$ \\
\hline Low (D) & $\mathrm{L}$ & $\mathrm{L}$ & M & S & S \\
\hline Very Low (E) & $\mathrm{L}$ & $\mathrm{L}$ & M & S & S \\
\hline
\end{tabular}

Where:

L : Low Risk

M : Moderate Risk

S : Significant Risk

$\mathrm{H}:$ High Risk

The mean value from the probability and impact values will be calculated by the following formula to categorize risk into three levels: High (RF>0.7), Moderate (RF 0.4 $0.7)$ and Low $(\mathrm{RF}<0.7)$.

$$
\mathrm{RF}=\mathrm{L}+1-(\mathrm{L} \times \mathrm{I})
$$

Where:

$\mathrm{RF}=$ Risk Factor; Scale $1-10$

$\mathrm{P}=$ Probability

I = Impact

\section{CONCEPTUAL DESIGN OF THE SHIARL PROJECT}

The valuable data gained from primary and secondary data were used to create innovative ideas for the SHIARL project. These were generated from various sources such as transport problems in Greater Jakarta, targeted development rates set by the Government over a 20-year period and potential transportation development to be integrated in the project.

One of the problems in Jakarta is devastating annual floods during the monsoon season that periodically interfere with transport users' accessibility to the airport, which depends on the intercity highways and the Sediyatmo Highway. The dependency also leads to congestion and travel time uncertainty during peak hours while commuters are struggling to access or leave their offices. The increase of commuters using private vehicles is caused due to limited land availability and resultant high density in Jakarta, which impact city functions and people's activities.

On the other hand, road development, which provides accessibility for commuter vehicles, is less than 1 percent per year on average and when compared to over 1,000 new vehicles sold every day, roads are predicted to be highly congested by 2020 . Rail-based transport project development is arguably one of the best solutions to solve transportation problems in the Jakarta mega region. One potential railway project particularly noted to support urban development is the Mass Rapid Transit (MRT) Jakarta, which is planned along a $110.8 \mathrm{~km}$ distance divided into north and south corridors. The MRT is currently under construction. 
Table 4. Innovative Ideas for the SHIARL Project

\begin{tabular}{ll}
\hline \multicolumn{1}{c}{ Reference } & \multicolumn{1}{c}{ Innovative Ideas } \\
\hline $\begin{array}{l}\text { Limited land } \\
\text { Lack of public } \\
\text { Transportation }\end{array}$ & Underground Infrastructure \\
Floods & MRT integration \\
Communication Needs & Floods tunnel integration \\
Renewable Energy & Fiber optics integration \\
Increase Regional & Utilize natural resources (solar, kinetic energy) \\
Economy & Develop commercial areas (residences, business center) \\
\hline
\end{tabular}

Underground infrastructure is proposed as a solution due to limited land area development in Jakarta through the integration of the proposed MRT and the proposed Flood Control Tunnel (PRASTI Tunnel) that will be used to solve Jakarta's lack of public transportation, various infrastructure and annual flood conditions. Economic aspects also are considered that propose fiber optics integration in commercial areas to generate regional income. The application of renewable energy to the project is expected to increase efficiency and quality of the natural environment. These ideas are expected to lead to the development of a multi-functional tunnel, a public rail link and storm water infrastructure, known as the (PRASTI) Tunnel. The tunnel is divided into three levels: the first level serves as a flood control channe for storm water; the second level serves as an airport accessibility channel or a rail link through the SHIARL project; and the third level is expected to serve the MRT line. The visualization of PRASTI Tunnel levels can be seen on Figure 1.

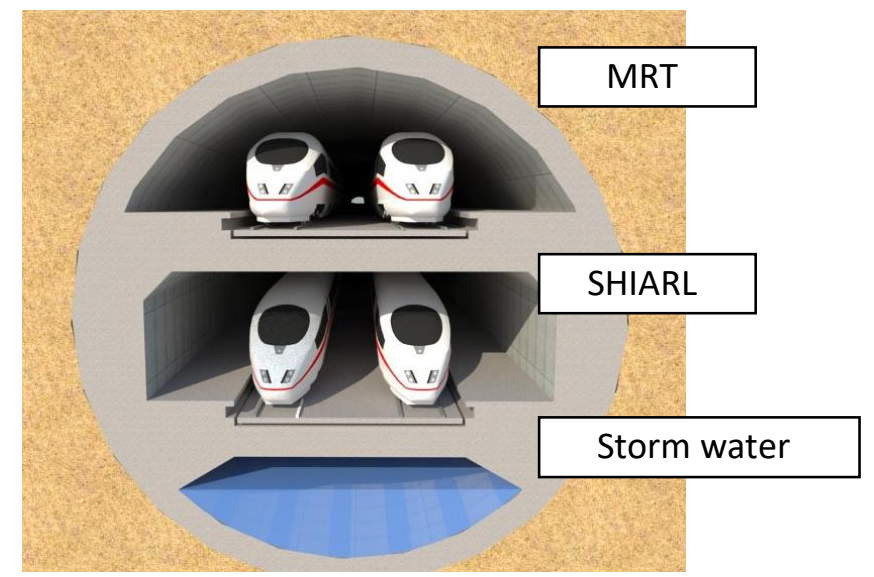

Figure 1. Cross Section of PRASTI Tunnel

\section{RISK ANALYSIS}

The purpose of the questionnaire survey is to determine major risks in the SHIARL project based on value engineering assessment. From 33 respondents, 52\% of them work in state-owned companies, $21 \%$ are working in the private sector and the rest, $27 \%$ are working in government agencies from various ministries. Educational background shows $73 \%$ of them hold a master's degree. Over $36 \%$ of respondents are working as engineers and $30 \%$ of them are managers, while 19\% have experience in infrastructure projects over the past 11-20 years.

The risk criteria in the SHIARL project are categorized into 9 criterion: planning and design, construction, operational and maintenance, railways technical operation, railways technical operation inside a tunnel, location, environmental, financial and institutional. The reliability test of 55 risk variables from the 33 respondents shows that Cronbach's Alpha value is about 0.929 or $>0.6$, therefore, the data is considered to be reliable. 
Table 5. Cronbach's Alpha Value of the SHIARL Project Risk Factor Variables

\begin{tabular}{crr}
\multicolumn{3}{c}{ Reliability Statistics } \\
\hline $\begin{array}{c}\text { Cronbach's } \\
\text { Alpha }\end{array}$ & $\begin{array}{c}\text { Cronbach's Alpha Based } \\
\text { on Standardized Items }\end{array}$ & $\begin{array}{c}\text { N of } \\
\text { Items }\end{array}$ \\
\hline .929 & .930 & 55 \\
\hline
\end{tabular}

From the descriptive analysis and inferential statistics, an analysis then was conducted using the Analytic Hierarchy Process (AHP) to determine the risk ranking from the risk variables. The ranking will consider the Risk Factor (RF) value where RF>0.7 will be categorized into high-risk variables and their needs to be mitigated.

The results show the category of risk has to be considered in more detailed designs of the SHIARL project. In the design and planning category, four out of five risks consist of failure in designing appropriate routes, failure to achieve project objectives, failure in construction design and failure in selecting suitable technology are ranked higher, which indicate how these risks play significant roles in the project's success. Meanwhile, four risks in the operational category require further mitigation strategies. These risks include: poor ventilation system control (when pressure and temperature levels are increased), potential pollution from noise and vibration, the absence of procedures and evacuation routes in case of accidents and/or fires.

Mega projects such as SHIARL will constantly involve huge costs in every aspect of their design from the concept stage to the operations stage. The questionnaire survey indicates resultant risks in the financial category that have to be considered, consisting for example, of the number of users that do not match the demand forecast, problems with identifying sources of financing, the long duration of return on project investment (payback period). Major risks variables are summarized as shown below in Table 6 .

Table 6. Major Risks in the SHIARL Project

\begin{tabular}{|c|c|c|c|c|}
\hline Variable & Risk & Type of Risk & Ranking & $\begin{array}{c}\text { RF } \\
\text { Value }\end{array}$ \\
\hline $\mathrm{X} 1$ & Failure in Selecting Route & Design and Planning & 1 & 0,838 \\
\hline $\mathrm{X} 7$ & Failure to achieve project objectives & Design and Planning & 2 & 0,827 \\
\hline $\mathrm{X} 3$ & Failure in construction design & Design and Planning & 3 & 0,774 \\
\hline $\mathrm{X} 5$ & Failure in technology selection & Design and Planning & 4 & 0,765 \\
\hline $\mathrm{X} 40$ & $\begin{array}{l}\text { Potential geological problems (most land in } \\
\text { Jakarta consist of sand deposits) }\end{array}$ & Environmental & 5 & 0,742 \\
\hline $\mathrm{X} 51$ & $\begin{array}{l}\text { Number of users does not match demand } \\
\text { forecast }\end{array}$ & Financial & 6 & 0,739 \\
\hline X29 & $\begin{array}{l}\text { Poor ventilation system control (when } \\
\text { pressure and temperature are increased) }\end{array}$ & Operational & 7 & 0,729 \\
\hline X39 & $\begin{array}{l}\text { Potential topography problem (Jakarta } \\
\text { contour tends to be equal/lower than the } \\
\text { high-water level) }\end{array}$ & Environmental & 8 & 0,717 \\
\hline $\mathrm{X} 45$ & Problem with sources of financing & Financial & 9 & 0,717 \\
\hline $\mathrm{X} 47$ & $\begin{array}{l}\text { Long duration of return on project } \\
\text { investment (payback period) }\end{array}$ & Financial & 10 & 0,716 \\
\hline $\mathrm{X} 26$ & Potential pollution on noise and vibration & Operational & 11 & 0,714 \\
\hline $\mathrm{X} 2$ & $\begin{array}{l}\text { Unaligned to the city planning and } \\
\text { government policy }\end{array}$ & Design and Planning & 12 & 0,708 \\
\hline $\mathrm{X} 30$ & The absence of procedures and evacuation & Operational & 13 & 0,707 \\
\hline
\end{tabular}




\begin{tabular}{clccc}
\hline Variable & \multicolumn{1}{c}{ Risk } & Type of Risk & Ranking & $\begin{array}{c}\text { RF } \\
\text { Value }\end{array}$ \\
\hline & route in case of an accident & Construction & 14 & 0,702 \\
X11 & Cost Overruns & Operational & 15 & 0,700 \\
X25 & Fire & & \\
\hline
\end{tabular}

In this research, identified major risks will be further investigated through risk mitigation that aims to reduce the probability and impact of an event into an acceptable threshold level. Performing mitigation strategies are arguably an effective way to reduce risk events in an infrastructure project (Haghnegahdar \& Ashgarizadeh, 2008). In this study, risk mitigation will be categorized into preventive and corrective actions as follows:

a. Failure in Selecting Route

The selected route fails to achieve the estimated number of passengers in the feasibility study. Incorrect placement of stations is one of the mistakes that will reduce revenues from ticketing and decrease services for airport rail link users. Thus, it is crucial to carefully determine suitable routes by considering business aspects and catchment areas related to annual flood conditions in Greater Jakarta. It will not only reduce traffic congestion, but also solve flooding problems.

Preventive action: Collect accurate data about catchment areas and potential flood levels during the feasibility study.

Corrective action: Optimize selected route performance. The flood control functions could be improved by connecting flood catchment areas and waduks (reservoirs) to reduce overflow into the Ciliwung River basin. Meanwhile, the lack of interest in water management issues from users can be improved by constructing feeders to enable the flood waters to reach out stations and to collaborate with developers to increase demand for infrastructure.

b. Failure to achieve project objectives

One of the causes of failure to achieve project objectives is the lack of information and lack of communication among stakeholders of the project. The impact of this situation will require redesign which greatly contributes to the cost increases and project delays.

Preventive action: Collect detailed information related to the project development, provides regular reports and evaluations strictly from decision makers.

Corrective action: Optimize design with minimum cost and minimum time.

c. Failure in construction design

The discovery of design errors during the construction process will cause additional cost and unexpected delays. The impact will be additional work orders and revised design. One of many reasons this risk occurs is misleading information that is used as input during the design process.

Preventive action: Ensure all the data is correct, conduct a comprehensive review.

Corrective action: Investigate scope, method of works and other aspects in detail, Perform optimization and adjustment.

d. Failure in technology selection

Unsuitable selection of technologies in design stage will affect significantly the operations stage. The selected technology should be taken into account along with maintenance, resources and local context.

Preventive action: Benchmarking, Testing, Collecting information.

Corrective action: Upgrading current technology 
e. Potential geological problems (Most land in Jakarta consists of sand deposits)

These potential geological problems could result in landslides and the collapse of soil at the location of the project. Lack of land support for the upper structure is one of the reasons this problem could occur.

Corrective action: Perform a grouting process to improve land support. Its application aims to improve soil resistance and prevent excessive degradation or settlement.

f. Number of users does not match demand forecast

This situation leads to a significant decrease in the amount of revenue.

Preventive action: Collaborate with the government in providing minimum guarantee of revenue/users

Corrective action: Collaborate with developers to generate users, Improve services

g. Poor ventilation system control (when pressure and temperature are increased)

The impact of this risk will increase the pressure and temperature in the tunnel drastically. Causes of a poor ventilation system are the reduced capacity of oxygen due to the lack of air flow without air control

Preventive action: Providing a control room to maintain pressure and temperature

Corrective action: Create a ventilation system using a jet flange (to produce air flow) and dampers (to control air flow and air pressure)

h. Potential topography problem (Jakarta contours tend to be equal/lower than the highwater level, resulting in subsidence)

Preventive action: Conducting a detailed soil bearing survey

i. Problem with sources of financing

This risk will leads to project delays and additional cost. It occurs through changes in macro-economic conditions or a financial crisis of the development consortium or the economy.

Preventive action: Reviewing financial capital sources in detail

Corrective action: Financial bonds

j. Long duration of return on project investment (payback period)

The length of time for the return on investment is not in accordance with the expected business plan. The expected payback period fails due to lack of demand from users, resulting in delays in capital return.

Preventive action: Optimizing service to improve users' interest

k. Potential pollution from noise and vibration

Strong noise and vibration pollution occurs while operating the train in the tunnel that is due to the massive use of a slab track, which then reduces the flexibility of tracks that can affect the users' comfort, causing damage to hearing.

Preventive action: Construct concrete floating slab track with rubber bearings to reduce noise and vibration

1. Unaligned with the city planning and government policy

Reroute and redesign the project during the design and planning stage. The lack of information and communication with related stakeholders become the major causes for this risk. 
Preventive action: Conduct adjustment(s) to the urban development plan, Negotiate with related stakeholders to achieve common goals.

$\mathrm{m}$. The absence of procedures and evacuation routes in case of accident(s)

Users are unable to escape/find safe place of refuge when the accident(s) occur. It could happen because the evacuation route is not designed properly.

Preventive action: Create detailed planning by taking into account safety and security

n. Cost Overrun

The project requires additional costs to finish because of this risk. One of the reasons this risk occurs is because of an unclear scope of the project and delays in the construction phase.

Preventive action: Ensure all the data are correct, Conduct a comprehensive design and planning assessment.

Corrective action: Investigate scope, method of works and other aspects in detail, Perform optimization and adjustments

o. Fire

It will cause death from inhaling smoke.

Preventive action: Create detailed evacuation routes, Create monitoring and controlling systems to prevent fire in tunnel

Corrective action: Create a ventilation system to release smoke from the tunnel using axial fans and provide an Authorized Program Analysis Report (APAR).

\section{CONCLUSION}

One of the solutions to improve the feasibility of the Soekarno-Hatta International Airport Rail Link (SHIARL) project is by using Value Engineering (VE) and Risk Management (RM) approach. Application of VE in Single Sideband (SSB) noise control will provide innovation, create efficiency and stimulate new technological breakthroughs, while Risk Management will reduce uncertainty, create a priorities scale and balance resource allocation. Therefore, the combination of these two approaches is expected to provide recommendations and accountability for decision makers.

VE in this study produces additional functions as the integration of MRT, flood control tunnel, and utilities which are expected not only to solve transportation problem, but also flood conditions in Jakarta. On the other hand, the RM process points out major risks that have to be considered. From the 55 variables identified as potential risks that can be affecting the SHIARL project, 15 of them are categorized as high-potential risk factors with a Risk Factor (RF) value above 0.7. There is a 33\% risk from design and planning, $26 \%$ from operational, $20 \%$ from financial risk and the rest from environment and construction risks. The ranking was summarizing in sequence as follows (See Table 6):

- Failure in Route Selection

- Failure to achieve project objectives

- Failure in construction design

- Failure in technology selection

- Potential geological problems (Most land in Jakarta consists of sand deposits)

- Number of users does not match demand forecast

- Poor ventilation system control (when pressure and temperature are increased)

- Potential topography problem (Jakarta contours tend to be equal/lower than the highwater level)

- Problem with sources of financing 
- Long duration of return on project investment (payback period)

- Potential pollution from noise and vibration

- Unaligned with the city planning and government policy

- The absence of procedures and evacuation routes in case of an accident

- Cost Overruns

- Fire

In this study, risk mitigation will be categorized into preventive and corrective actions. Technology selection and detail design of structures play a significant role to mitigate potential risks that could occur in the project. It can be seen from the use of a grouting method to improve land support, a jet flange (to generate airflow), the use of dampers (control flow and air pressure), and axial fans for removing smoke resulting from the occurrence of a fire inside the tunnel, as well as the use of rubber bearings on a concrete floating slab track to prevent excessive vibration and noise.

\section{REFERENCES}

Berawi, M. A., Susantono, B., Miraj, P., Berawi, A. R. B., Rahman, H. Z., \& Husin, A. (2014). Enhancing Value for Money of Mega Infrastructure Projects Development Using Value Engineering Method. Procedia Technology, 16, 1037-1046.

Berawi, M. A., \& Susantono, B. (2012). Developing Conceptual Design of Mega Infrastructure Project: Creating Innovation and Added Value. Value World,35(1), 12-20.

Tang, S., \& Lo, H. K. (2008). The impact of public transport policy on the viability and sustainability of mass railway transit - The Hong Kong experience. Transportation Research Part A: Policy and Practice, 42(4), 563-576.

Grimsey, D., \& Lewis, M. K. (2005). Are Public Private Partnerships value for money?: Evaluating alternative approaches and comparing academic and practitioner views. In Accounting Forum (Vol. 29, No. 4, pp. 345-378). Elsevier.

Dell'Isola, A. (1997), Value Engineering : Practical Application for Design Construction Maintenance \& Operations, R.S. Means Company, Inc., Kingstone, USA.

Haghnegahdar, L., \& Asgharizadeh, E. (2008,). The Risk and Value Engineering Structures and their Integration with Industrial Projects Management (A Case Study on IK Corporation). In Proceeding of World Academy of Science, Engineering and Technology (Vol. 30).

Janic, M., \& Reggiani, A. (2002). An application of the multiple criteria decision making (MCDM) analysis to the selection of a new hub airport. European journal of transport and infrastructure research EJTIR, 2 (2).

Jin, X. H., \& Zhang, G. (2011). Modelling optimal risk allocation in PPP projects using artificial neural networks. International journal of project management, 29(5), 591-603.

Ke, Y., Wang, S., Chan, A. P., \& Lam, P. T. (2010). Preferred risk allocation in China's public-private partnership (PPP) projects. International Journal of Project Management, 28(5), 482-492.

Yoo, K. E., \& Choi, Y. C. (2006). Analytic hierarchy process approach for identifying relative importance of factors to improve passenger security checks at airports. Journal of Air Transport Management, 12(3), 135-142.

Zietsman, D., \& Vanderschuren, M. (2014). Analytic Hierarchy Process assessment for potential multi-airport systems - The case of Cape Town. Journal of Air Transport Management, 36, 41-49.

Zou, Patrick XW, Shouqing Wang, and Dongping Fang. "A life-cycle risk management framework for PPP infrastructure projects." Journal of financial management of property and construction 13.2 (2008): 123-142. 